\title{
PELATIHAN PENINGKATAN SELF CONCEPT DAN SELF ACCEPTANCE PADA WARGA BINAAN DI LP PEREMPUAN KELAS II A MARTAPURA
}

\author{
Eka Sri Handayani, Rudi Haryadi, Akhmad Rizkhi Ridhani, dan Zainal Fauzi \\ Fakultas Keguruan dan Ilmu Pendidikan, Universitas Islam Kalimantan \\ E-mail : ekasrihandayani678@gmail.com
}

\begin{abstract}
ABSTRAK
Dalam lembaga pemasyarakatan, narapidana termasuk narapidana wanita yang melakukan tindak pidana menghadapi sejumlah permasalahan yang sangat berpengaruh terhadap psikologis mereka. Kehidupan yang dijalani seorang narapidana selama berada di penjara, membuat dirinya menghadapi berbagai masalah psikologis antara lain kehilangan keluarga, kehilangan kontrol diri, kehilangan model, dan kehilangan dukungan. Konsep diri yang positif adalah modal dalam berinteraksi di kehidupanbermasyarakat. Konsep diri positif membuat individu mampu menerima perbedaan antarpribadi dan mengatasi konflik secara konstruktif (Rogers dalam Batista, 2012). Konsep diri yang negatif membawa individu pada perasaan minder, harga diri yang rendah dan memunculkan perilaku yang tidak mendukung interaksi hubungan interpersonal.West dan Turner (2008) mengemukakan definisi konsep diri sebagai halyang ingin ditampilkan individu pada individu lain. Peserta dengan jumlah 30 orang (Peserta Warga Binaan) yang mengikuti pelatihan, umumnya mendapatkan kenaikan skor dari sebelumnya dalam kategori sedang dan meningkat menjadi masuk dalam kategori tinggi, pada skala Self Concept dan pada aspek atau pengukuran Self Acceptance, bisa di lihat dari semua peserta sebanyak 30 orang (Peserta Warga Binaan) yang mengikuti pelatihan, sebelumnya mendapatkan kategori rendah untuk penerimaan diri mereka, setelah mendapatkan pelatiihan mereka lebih bisa menerima keadaan dan menyesuaiakan diri dengan lingkungan selama menjadi Warga Binaan di Lapas Kelas II A Martapura.
\end{abstract}

Kata Kunci : Self Concept, Self Acceptance, Warga Binaan LAPAS Perempuan

\section{PENDAHULUAN}

Dalam lembaga pemasyarakatan, narapidana termasuk narapidana wanita yang melakukan tindak pidana menghadapi sejumlah permasalahan yang sangat berpengaruh terhadap psikologis mereka. Kehidupan yang dijalani seorang narapidana selama berada di penjara, membuat dirinya menghadapi berbagai masalah psikologis antara lain kehilangan keluarga, kehilangan kontrol diri, kehilangan model, dan kehilangan dukungan. Selain itu tembok lapas juga merenggut kebebasan atau kemerdekaan bergerak. Narapidana juga akan mengalami kehidupan yang lain dengan kehidupan yang sebelumnya antara lain kehilangan hubungan dengan lawan jenis, kehilangan hak untuk menentukan segala sesuatunya sendiri, kehilangan hak memiliki barang, kehilangan hak 
mendapat pelayanan dan kehilangan rasa aman. Berbagai permasalahan tersebut merupakan gangguan yang akan mempengaruhi narapidana baik Secara fisik maupun psikologis. (Clara Priscilla Meilina, 2013:4).

Ajaran islam sangat menjunjung tinggi derajat perempuan bahkan menjunjung tinggi derajat perempuan ahkan dalam hadits Nabi diriwayatkan bahwa surga itu berada di bawah telapak kaki ibu. Dalam hadist lain dikatakan ketika Rasulullah di tanya siapakah ketika orang yang pertamatama harus di hormati di dunia ini. Beliau menjawab "Ibumu". Jawaban ini terus berulang-ulang oleh rasulullah sampai tiga kali, ke empat barulah beliau menjawab "lalu ayahmu" (Listyani, dkk,2019), tentu dalam hal ini sebagai individu dalam status sebagai narapidana wanita, akan banyak peran yang tergantikan, terutama sebagai seorang istri dan juga seorang ibu, oleh karena itu dalam menyikapinya di pelukan konsep diri yang positif agar terbangun citra diri positif dan modal diri untuk mampu beradaptasi dan berinteraksi dalam lingkungan sosial.

Konsep diri yang positif adalah modal dalam berinteraksi di kehidupan bermasyarakat. Konsep diri positif membuat individu mampu menerima perbedaan antar pribadi dan mengatasi konflik secara konstruktif (Rogers dalam Batista, 2012). Konsep diri yang negatif membawa individu pada perasaan minder, harga diri yang rendah dan memunculkan perilaku yang tidak mendukung interaksi hubungan interpersonal.

Narapidana mengalami kehilangan kebebasan, rasa aman dan nyaman, terpisah dari keluarga dan komunitas sebelumnya. Perubahan seseorang menjadi narapidana bukanlah hal yang mudah, maka butuh dukungan sosial yaitu keluarga yang mau menerima, demikian hal yang d alami para narapidana perempuan di Lapas Kelas II A Martapura, Hal ini dibutuhkan sebagai modal beradaptasi dengan lingkungan yang terbatas sehingga dapat menekan masalah psikis terutama berkurangnya rasa percaya diri dan rasa kurang dihargai.

\section{KHALAYAK SASARAN}

Khalayak sasaran dalam kegiatan pengabdian ini adalah para Warga Binaan Pemasyarakatan di Lapas Perempuan Kelas II A Martapura 


\section{METODE PENELITIAN}

Bentuk

kegiatan

yang

diselenggarakan yaitu serangkaian

kegiatan yang dilaksanakan dalam

bentuk materi, diskusi dan treatmen yang meliputi:

Penyampaian materi mengenai:

1. Memberikan materi tentang self concept dan self acceptance Eka Sri Handayani, M.Psi, Psikolog dan Rudi Haryadi M. Pd

2. Memberikan training atau pelatihan untuk meningkatkan self concept dan self acceptance Eka Sri Handayani, M.Psi, Psikolog, Rudi Haryadi, M.Pd, Akhmad Rizkhi Ridhani M. Pd, Kons.

3. Pendampingan dalam memberikan materi dan training untuk meningkatkan self concept dan self acceptance Rudi Haryadi, M.Pd, Akhmad Rizkhi Ridhani M. Pd, Kons, dan Zainal Fauzi, M.Pd, Kons.

4. Training : Training atau pelatihan untuk meningkatkan self concept dan self acceptance

\section{HASIL DAN PEMBAHASAN}

Kegiatan pengabdian kepada masyarakat ini dilaksanakan pada tanggal 25 februai 2020. Kegiatan di mulai pada pukul 09.00 sampai dengan pukul 14.00 WITA, bertempat di Lapas Kelas II A Martapura. Kegiatan terapi ini diadakan berdasarkan laporan sipir dan beberapa warga binaan bahwa setelah mereka terkena kasus dan berada di penjara maka gambaran diri dan keercayaan diri menurun di karenakan sebagian terdapat masalah terhadap suami dan keluarga. Oleh karena itu dalam pelatihan kali ini disampaikan beberapa materi terlebih dahulu baru menggunakan teknik Role Playing dan praktek : Penyampaian Materi Peningkatan Self Concept dan Self Acceptance oleh Eka Sri Handayani M.Psi, Psikolog (Materi Terlampir) setelah diberikan materi audience diberikan Role Playing, mereka membuat kelompok terdiri dari 15 kelompok beranggotan 2 orang. Masing-masing kelompok mengerjakan tugas secara individual, dan role playing di lakukan masing-masing kelompok di tunjuk perwakilan dan anggota kelompok lainnya memberikan penilaian. Materi dari keterampilan tersebut sebagai berikut : Para Warga Binaan di LAPAS Kelas II A diminta Untuk menggambar jari dengan penjelasan sebagai berikut :

- Dalam gambar ibu jari 
menggambarkan "Pengalaman

BAHAGIA

- Dalam Gambar Jari telunjuk Menggambarkan "Pengalaman SEDIH"

- Dalam Gambar Jari Tengah menggambarkan "SIFAT BURUK"

- Dalam Gambar jari Manis "SIFAT YANG DISUKAI PADA TEMAN"

- Dalam gambar Jari Kelingking "SIFAT YANG TIDAK DISUKAI PADA TEMAN"

- Dalam Gambar Telapak Tangan tuliskan "HAL POSITIF DALAM DIRI"

Setelah mereka melakukan dan menuliskan semua pengalaman dengan menggambar jari maka mereka diminta untuk menjelaskan di depan temantemannya dengan menjelaskan apa yang dirasakannya dan dikesankannya.

Pendampingan materi Peningkatan Self Concept dan Self Acceptance Oleh Rudi Haryadi M.Pd

Wubbolding (dalam Corey, 2013) mengembangkan sistem WDEP. Setiap huruf dari WDEP mengacu pada kumpulan strategi:

- $\mathrm{W}=$ wants and needs (keinginankeinginan dan kebutuhankebutuhan),
- $\mathrm{D}=$ direction and doing (arah dan tindakan),

- $\mathrm{E}=$ selft evaluation (evaluasi diri), dan

- $\mathrm{P}=$ planning $($ perencanaan $)$, dengan Eksplorasi keinginan, kebutuhan dan persepsi (want and needs) Dalam tahap eksplorasi keinginan, kebutuhan, Eksplorasi kebutuhan dan keinginan dilakukan terhadap kebutuhan dan keinginan dalam segala bidang, meliputi kebutuhan dan keinginan terhadap keluarga, orang tua, teman- dan lain-lain.

a. Kepribadian seperti apa yang kamu inginkan?

b. Jika kebutuhanmu dan keluargamu sesuai, maka kamu ingin keluargamu seperti apa?

c. Apa yang kamu lakukan seandainya kamu penuhi dalam kehidupan ini?

Hal ini berupa untuk mengetahui sejauh mana keinginan dan kebutuhan peserta berkaitan dengan self acceptance.

- Eksplorasi arah dan tindakan (direction and doing)

Eksplorasi pada tahap ini dilakukan untuk mengetahui apa saja yang telah dilakukan peserta guna 
mencapai kebutuhannya. Tindakan yang dilakukan oleh peserta yang diekplorasi yang berkaitan dengan masa sekarang. Tindakan atau perilaku masa lalu juga boleh di ekplorasi asalkan berkaitan dengan tindakan masa sekarang dan membantu individu membuat perencanaan yang lebh baik dimasa mendatang. Dalam melakukan ekplorasi arah dan tindakan, fasilitator berperan sebagai cermin bagi peserta.

- Evaluasi diri (self evaluation)

Tahap ini dilakukan untuk mengevaluasi tindakan yang dilakukan fasilitator dalam rangka memenuhi kebutuhan dan keinginannya: keefektifan dalam memenuhi kebutuha. Beberapa pertanyaan yang dapat digunakan untuk memandu tahap ini:

1. Apakah yang kamu lakukan menyakiti atau membantumu memenuhi kebutuhan?

2. Apa perilakumu sekarang bermanfaat bagi kamu?

3. Apakah ada kesesuaian antara yang kamu lakukan dengan yang kamu inginkan?

4. Apakah yang kamu lakukan melangar aturan?
5. Apakah yang kamu inginkan dapat dicapai atau realistik?

6. Apakah kamu menguji keinginanmu, apakah keinginanmu benar-benar keinginan terbaikmu dan orang lain?

Setelah proses evaluasi diri ini diharapkan peserta dapat melakukan evaluasi diri bagi dirinya secara mandiri. Dengan kesadaran kejiwaan, tanpa merasa marah dan kecewa dibelakang. Dalam hal self-acceptance fasilitator memberikan pemahaman pada peserta tentang kekurangan pada dirinya sebaiknya dapat diterima sebagai dirinya yang tuh, sehingga nantinya peserta dapat menerima kekurangan dan kelebihan dirinya secara utuh. Dengan mengimplementasi nilai tersebut adalah pendekatan pembelajaran yang berpengalaman.

- Rencana dan tindakan (planning) Ini adalah tahap terakhir dalam konseling realitas. Di tahap ini fasilitator bersama peserta membuat rencana tindakan guna membantu peserta memenuhi keinginan dan kebutuhannya. Bentuk kegiatan yang diselenggarakan yaitu 


$\begin{array}{ll}\text { serangkaian kegiatan yang } & \text { kebutuhan hidupnya, karena } \\ \text { dilaksanakan dalam bentuk materi, } & \text { manusia tidak di ciptakan sendiri, } \\ \text { pelatihan mengenai perihal } & \text { dan tidak ada manusia yang bisa } \\ \text { keterampilan self concept dan self } & \text { hidup sendiri. (Rachmayani,dkk, } \\ \text { acceptance serta evaluasi. Tujuan } & \text { 2020). Dalam menunjang hal } \\ \text { dari pelatihan ini memberikan } & \text { tersebut maka diperlukan } \\ \text { materi self concept dan } & \text { kemampuan konsep diri dan } \\ \text { memberikan pelatihan tentang } & \text { penerimaan diri yang baik pula. } \\ \text { bagaimana mengenali self concept } & \text { Bentuk evaluasi dari kegiatan } \\ \text { dan bagaimana meningkatnya dan } & \text { pengabdian kepada masyarakat ini } \\ \text { mengetahui bagaimana self } & \text { dapat dilihat dari hasil kuesioner } \\ \text { acceptance. Seyogyanya manusia } & \text { yang disebarkan kepada peserta } \\ \text { harusdi haruskan untuk berinteraksi } & \text { kegiatan dan telah dianalisis serta } \\ \text { dan berkomunikasi dengan orang } & \text { dituangkan kedalam sebuah data di } \\ \text { lain, di lingkunganna untuk } & \text { bawah ini : }\end{array}$

Tabel 1. Kategori Interval Skor Rata-Rata Penilaian Pemahaman Peserta

\begin{tabular}{cc}
\hline Interval & Kategori \\
\hline $11-14$ & Tinggi \\
$7-10$ & Sedang \\
$3-6$ & Rendah \\
\hline
\end{tabular}

SKALA KONSEP DIRI

Sumber: data primer diolah (2020)

SKALA PENERIMAAN DIRI

\begin{tabular}{cc}
\hline Interval & Kategori \\
\hline $11-14$ & Tinggi \\
$7-10$ & Sedang \\
$3-6$ & Rendah \\
\hline
\end{tabular}

Sumber: data primer diolah (2020)

Secara umum gambaran pelatihan dalam meningkatkan self concept dan self acceptance yang di laksanakan kepada warga binaan di LP kelas II A 
Martapura sebelum dilaksanakan pelatihan berada pada kategori rendah dengan peroleh rata-rata Self Concept 79.33 dan 86.75

Secara umum gambaran hasil dari pelatihan peningkatan self concept mengalami peningkatan dengan ratarata 69.23 yang termasuk dalam kategori rendah, setelah mendapatkan pelatihan self concept didapatkan ratarata sebesar 79.33 dalam karegori sedang artinya pelatihan self concept mampu meningkatkan kemampuan self concept pada Warga Binaan di Lapas Kelas II A Martapura sedangkan dalam pelatihan peningkatan Self Acceptance mengalami peningkatan sebelum diberikan pelatihan di dapatkan rata-rata 69.91 dalam kategori rendah, kemudian setelah mendapatkan pelaltihan Self Acceptance meningkat dengan rata-rata 86.75 hal ini masuk dalam ketgori tinggi

Gambaran keterampilan pelatihan peningkatan self concept dan self acceptance dapat dilihat dari grafik 1 dan grafik 2 .

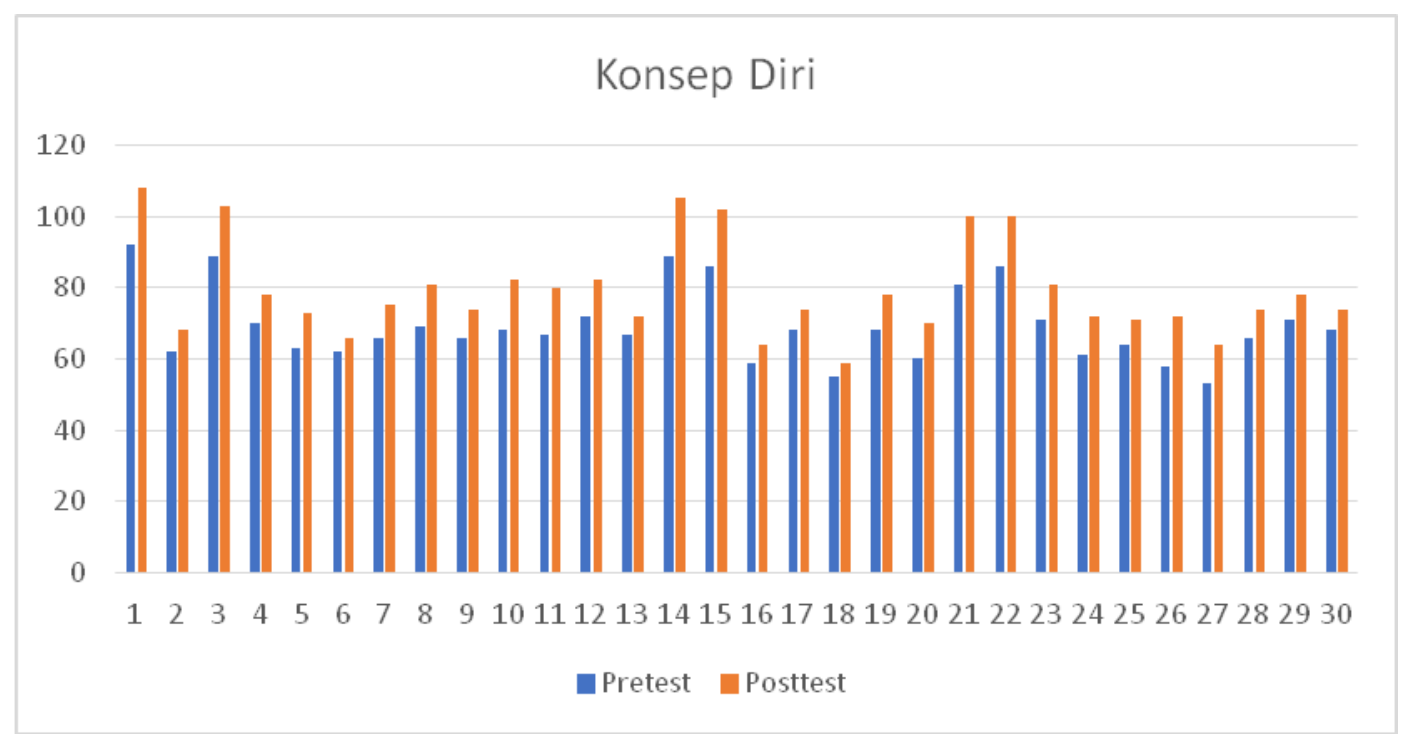

Grafik 1. gambaran pretest-posttest Self Concept 


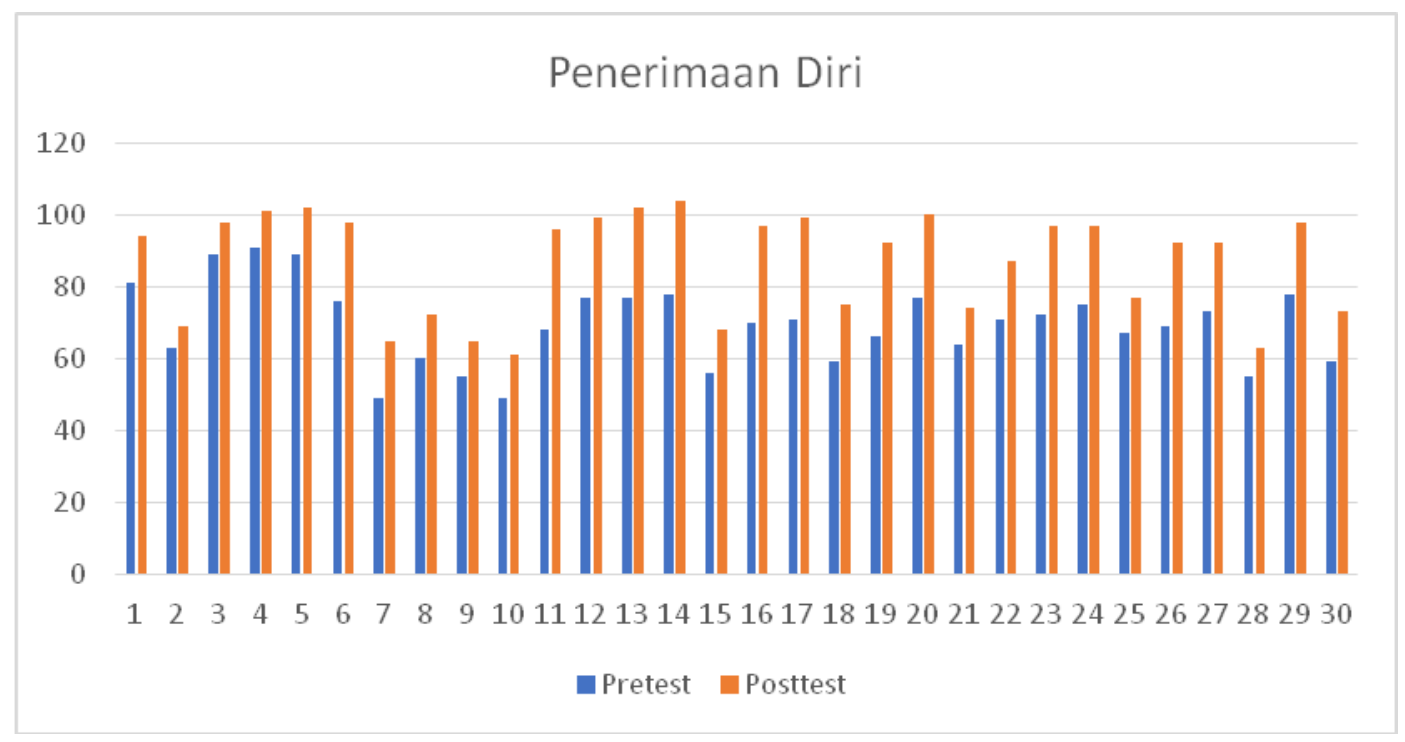

Grafik 2. gambaran pretest-posttest Self Acceptance

Dari grafik tersebut di atas bisa di gambarkan setiap peserta dengan jumlah 30 orang (Peserta Warga Binaan) yang mengikuti pelatihan, umumnya mendapatkan kenaikan skor dari sebelumnya dalam kategori sedang dan meningkat menjadi masuk dalam kategori tinggi, pada skala Self Concept dan pada aspek atau pengukuran Self Acceptance, bisa di lihat dari semua peserta sebanyak 30 orang (Peserta Warga Binaan) yang mengikuti pelatihan, sebelumnya mendapatkan kategori rendah untuk penerimaan diri mereka, setelah mendapatkan pelatiihan mereka lebih bisa menerima keadaan dan menyesuaiakan diri dengan lingkungan selama menjadi Warga Binaan di Lapas Kelas II A Martapura.
Berikut Foto-Foto Kegiatan Pelaksanaan Pengabdian kepada Masyarakat :
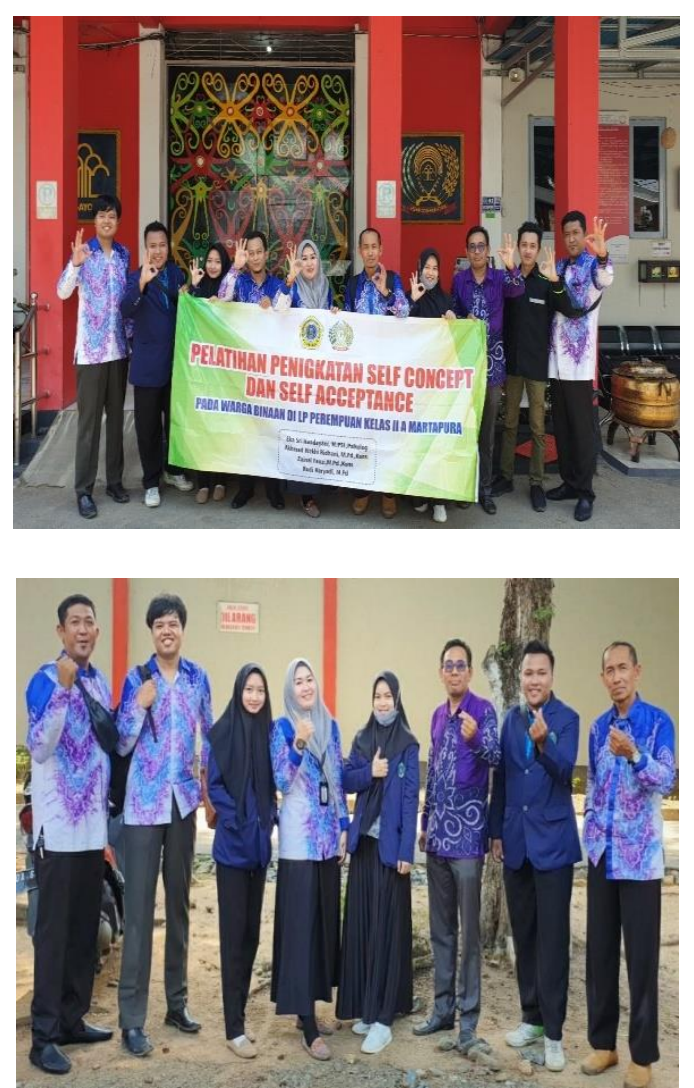

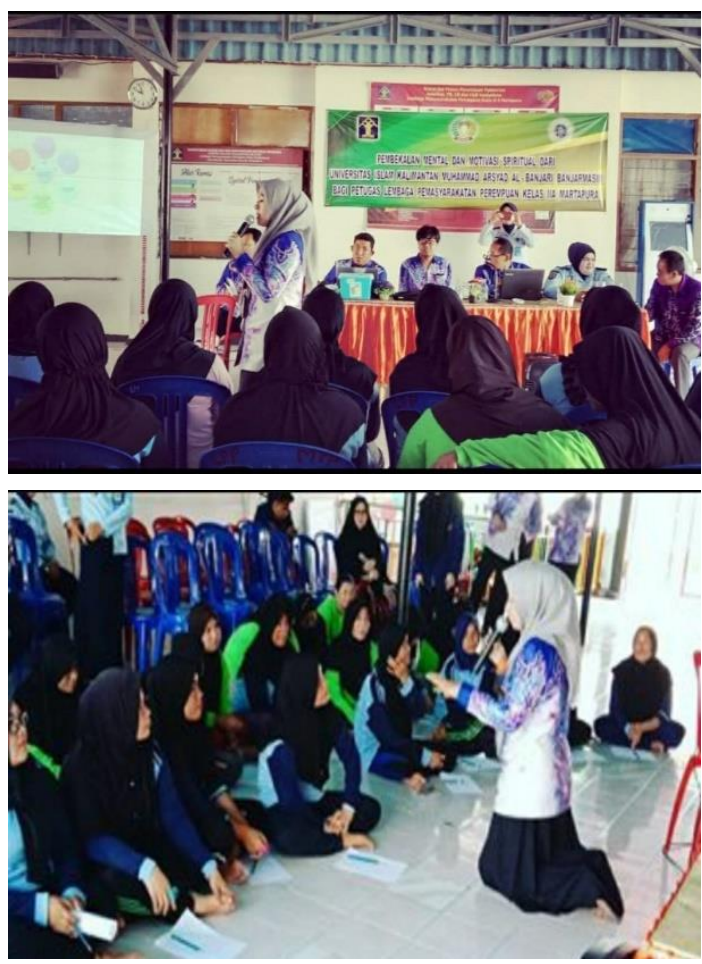

\section{KESIMPULAN}

Pelaksanaan kegiatan berlangsung sangat baik dan berjalan dengan sukses. Hal ini terlihat dari keantusiasan para peserta disetiap sesi kegiatan. Diharapkan setelah kegiatan ini agar peserta kegiatan mampu mengaplikasikan keterampilan self concept dan self acceptance ini seharihari pada kegiatan. Agar mampu mengenal diri lebih baik lagi dan mampu menerima diri keadaan diri dan menyesuaikan diri sehingga mampu mengerjakan berbagai kegiatan selama menjadi Warga Binaan dan mengambil manfaat dari setiap kegiatan yang diselnggrakan baik kepada pembangunan karakter diri juga pengembangan diri pada umumnya.

Tujuan dari pelatihan ini memberikan materi self concept dan memberikan pelatihan tentang bagaimana mengenali self concept dan bagaimana meningkatkanya dan mengetahui bagaimana self acceptance, dengan memberikan pelatihan kepada 30 orang Warga Binaan yang sudah terpilih dalam kategori kelas aktif atau Warga Binaan yang masih terlibat banyak permasalahan selama di dalam Lapas, sehingga dengan kegiatan ini akan bermanfaat kedepannya sebagai bahan pembelajaran dan akan di praktekan sendiri di kemudian hari.

Bentuk evaluasi dari kegiatan pengabdian kepada masyarakat ini setelah dianalisis menghasilkan data dengan kategori Secara umum gambaran hasil dari pelatihan peningkatan self concept mengalami peningkatan dengan rata-rata 69.23 yang termasuk dalam kategori rendah, setelah mendapatkan pelatihan self concept didapatkan rata-rata sebesar 79.33 dalam karegori sedang artinya pelatihan self concept mampu meningkatkan kemampuan self concept pada Warga Binaan di Lapas Kelas II A Martapura sedangkan dalam pelatihan 
peningkatan Self Acceptance mengalami peningkatan sebelum diberikan pelatihan di dapatkan rata-rata 69.91 dalam kategori rendah, kemudian setelah mendapatkan pelaltihan Self Acceptance meningkat dengan rata-rata 86.75 hal ini masuk dalam ketgori tinggi.

\section{DAFTAR PUSTAKA}

American Psychiatric Association (APA),. Practice Gaudelines for the Psychiatric Evaluation of Adults. (3rd). USA: APA

Desmita. 2015.2 Psikologi Perkembangan. Bandung: PT. Remaja Rosdakarya

Chaplin, J.P. 2011. Kamus Lengkap Psikologi Diterjemahkan oleh Kartini Kartono.Jakarta: PT. Raja Grafindo Persada

Hurlock, Elizabeth B.1997. Psikologi Perkembangan Jilid . Jakarta: Erlangga

Meilina Clara Priscilla, 2013. Skripsi: Dampak Psikologis Bagi Narapidana Wanita yang Melakukan Tindak Pidana
Pembunuhan dan Upaya

Penanggulangannya. Malang:

Universitas Brawijaya

Potter, Patricia; Perry, Anne Griffin, 2005. Buku Ajar: Fundamental Keperawatan, Konsep, proses dan praktik. Jakarta: Penerbit EGCGail W. Stuart, 2006. Buku Saku Keperawatan Jiwa. Jakarta: EGC

Karen Glanz, Barbara K. Rimer, K. Viswanath, 2008. Health Behavior And Health Education Theory, Research,and Practice. (4th.EDITION).

St. Fransisco:Jossey-Bass

Listyani, N, \& Ridhani M.E. Sosialisasi Tentang Kesadaran kedudukan wanita dalam perkawinan bagi warga binaan wanita di lembaga pemasyarakatan ; Jurnal Pengabdian Al Ikhas 5(2), hal.5

Rachmayanie.R \& Sulistiyana.S. Pelatihan Tekhnik Asertif Untuk Mengurangi Kecemasan Komunikasi Interpersonal Pada Siswa Kelas X SMA Negeri 12 Banjarmasin ; Jurnal Pengabdian Al-Ikhlas 5 (1); hal. 126

Santrock, John W. (2012). Life Span Development Jilid I (Edisi Ketigabelas). Jakarta: Erlangga 